\title{
Progesterone and Preterm Birth Prevention: Translating Clinical Trials Data into Clinical Practice
}

\author{
Vincenzo Berghella \\ Division of Maternal-Fetal Medicine, Department of Obstetrics and Gynecology, Jefferson Medical College \\ of Thomas Jefferson University
}

Follow this and additional works at: https://jdc.jefferson.edu/obgynfp

Part of the Obstetrics and Gynecology Commons

\section{Let us know how access to this document benefits you}

\section{Recommended Citation}

Berghella, Vincenzo, "Progesterone and Preterm Birth Prevention: Translating Clinical Trials Data into Clinical Practice" (2012). Department of Obstetrics and Gynecology Faculty Papers. Paper 21.

https://jdc.jefferson.edu/obgynfp/21

This Article is brought to you for free and open access by the Jefferson Digital Commons. The Jefferson Digital Commons is a service of Thomas Jefferson University's Center for Teaching and Learning (CTL). The Commons is a showcase for Jefferson books and journals, peer-reviewed scholarly publications, unique historical collections from the University archives, and teaching tools. The Jefferson Digital Commons allows researchers and interested readers anywhere in the world to learn about and keep up to date with Jefferson scholarship. This article has been accepted for inclusion in Department of Obstetrics and Gynecology Faculty Papers by an authorized administrator of the Jefferson Digital Commons. For more information, please contact: JeffersonDigitalCommons@jefferson.edu. 


\section{Progesterone and Preterm Birth Prevention: Translating Clinical Trials Data into Clinical Practice.}

\section{SMFM Clinical Guideline}

From the Society for Maternal-Fetal Medicine Publications Committee with the assistance of Vincenzo Berghella, Division of Maternal-Fetal Medicine, Department of Obstetrics and Gynecology, Jefferson Medical College of Thomas Jefferson University, Philadelphia, PA

Address all correspondence to:

The Society for Maternal-Fetal Medicine: Publications Committee.

409 12th Street, SW

Washington, DC 20024

Phone: 202-863-2476

Fax: 202-554-1132

E-Mail: pubs@smfm.org

Reprints will not be available 


\begin{abstract}
Objective: To provide evidence-based guidelines for utilization progestogens for the prevention of preterm birth (PTB).

Methods: Relevant documents, in particular randomized trials, were identified using PubMed (US National Library of Medicine, 1983 to February, 2012) publications, written in English, which evaluate the effectiveness of progestogens for prevention of preterm birth. Progestogens evaluated were, in particular, vaginal progesterone and 17-alpha hydroxyl-progesterone caproate (17P). Additionally, the Cochrane Library, organizational guidelines, and studies identified through review of the above were utilized to identify relevant articles. Data was evaluated according to population studied, with separate analyses for singleton vs multiple gestations, prior PTB, or short transvaginal ultrasound (TVU) cervical length (CL), and combinations of these factors. Consistent with U.S Preventive Task Force suggestions, references were evaluated for quality based on the highest level of evidence, and recommendations were graded.
\end{abstract}

Results and Recommendations: Summary of randomized studies indicates that in women with singleton gestations, no prior PTB, and short CL $\leq 20 \mathrm{~mm}$ at $\leq 24$ weeks, vaginal progesterone, either 90mg gel or 200mg suppository, is associated with reduction in PTB and perinatal morbidity and mortality, and can be offered in these cases. The issue of universal cervical length screening of singleton gestations without prior PTB for the prevention of preterm birth remains object of debate. Cervical length screening in singleton gestations without prior preterm birth cannot yet be universally mandated. Nonetheless, implementation of such a screening strategy can be viewed as reasonable, and can be considered by individual practitioners, following strict guidelines. In singleton gestations with prior PTB 20-36 6/7 weeks, 17P 250mg IM weekly, preferably starting at 16-20 weeks until 36 weeks, is recommended. In these women with prior 
preterm birth, if the TVU CL shortens to $<25 \mathrm{~mm}$ before 24 weeks, cervical cerclage may be offered. Progestogens have not been associated with prevention of PTB in women who have in the current pregnancy multiple gestations, preterm labor, or preterm premature rupture of membranes. There is insufficient evidence to recommend the use of progestogens in women with any of these risk factors, with or without a short CL.

Keywords: progestogens, vaginal progesterone, 17-alpha hydroxyl-progesterone caproate, prior preterm birth, cervical length, preterm birth 


\section{Introduction}

Progesterone was isolated and characterized in 1934, and its role in myometrial quiescence was first reported in 1954. (1,2) From 2003 to 2011, several randomized trials evaluating the effect of either 17 hydroxy-progesterone caproate (17P) given intramuscularly (IM), natural progesterone given vaginally or orally for prevention of preterm birth (PTB), have been published. The term 'progestogens' includes both vaginal progesterone and 17P.

Given this large amount of new important information, the scope of this manuscript is to review the level 1 evidence (RCTs, and meta-analyses of RCTs) evaluating the role of progestogens in the prevention of $\mathrm{PTB}$, and to provide clinicians with current recommendations for their use in possible clinical scenarios. Other publications have not addressed the totality of this new information. (3-5)

As $17 \mathrm{P}$ and vaginal progesterone may vary in their effect $(6,7)$, they will be addressed separately. The effects of interventions for reduction of PTB often vary by the population studied, and in particular by major risk factor categories for PTB. Major differences exist when analyzing effects of other interventions by number of fetuses (i.e. singleton vs multiple gestations), prior PTB (vs not), and short cervical length (CL) on transvaginal ultrasound (TVU) (vs not). (8). Therefore data will be analyzed according to these major categories of risk.

\section{What are the mechanism of action and safety data of progestogens?}

The mechanisms of action and safety of progestogens are not the purpose of this review, and are discussed only briefly. While the exact mechanism of action of progestogens in preventing preterm birth is unknown, several possibilities have been proposed. (Table 1) (9-17) In general, the evidence seems to favor 2 mechanisms: an anti-inflammatory effect that counteracts the 
inflammatory process leading to PTB, and a local increase in progesterone in gestational tissues that counteracts the functional decrease in progesterone leading to PTB. (Table 1) (9-17)

Regarding safety, several studies failed to detect any long term effect from the intrauterine exposure of the fetus to pharmacologic progestogens, even when given in the first trimester. (18) Follow-up, at a mean of 4 years, of 278 children randomized in the largest RCT evaluating 17P for prevention of recurrent PTB revealed no differences in physical examination, health status, or performance (motor, problem solving, personal-social) compared to placebo.

\section{What is the evidence and recommendation for use of progestogens for prevention of PTB}

in:

- Singleton gestations with no prior preterm birth, with unknown CL?

17P:

In 168 women in active military duty with only a 3\% rate of prior PTB and unknown CL, 17P 1,000mg IM weekly starting at 16-20 weeks was not associated with any effect on the incidence of PTB or perinatal outcomes compared to placebo. (20)

Vaginal progesterone:

No RCT has evaluated the effect of vaginal progesterone in this population.

In summary, there is insufficient evidence to determine the impact on PTB of progestogens in singleton gestations with no prior history of preterm birth, and with unknown or normal CL. 
- Singleton gestations with no prior PTB, but short CL?

17P:

It is particularly important to assess the effectiveness of progesterone in women without prior PTB, as most PTBs occur in this population. In 657 nulliparous women with singleton gestations with TVU CL $\leq 30 \mathrm{~mm}$ at 16-22 3/7 weeks, 17P 250mg intramuscularly weekly through 36 weeks was associated with similar incidences of preterm birth $<35$ weeks $(13.5 \%$ vs $16.1 \% ; \mathrm{p}=0.35)$ and $<37$ weeks ( 25.1 vs $24.2 \% ; \mathrm{p}=0.80$ ), compared to placebo. (21) This RCT was stopped due to a planned interim analysis that revealed further enrollment was statistically very unlikely to demonstrate a significant difference between the groups.

In 79 women with singleton pregnancies (66\% of whom had no prior PTB) with TVU CL $<25 \mathrm{~mm}$ between 16-24 weeks, 17P was associated with similar rates of preterm birth and neonatal morbidity and mortality compared to cerclage. (22) Cerclage was significantly more effective than 17P at reducing the incidences of PTB $<35$ weeks and $<37$ weeks in the subgroup with TVU CL $\leq 15 \mathrm{~mm}$. (22) This RCT was stopped before planned recruitment was completed as the authors stated that 'it had become impractical, unethical, and unreasonable to withhold progesterone from one study group.'

\section{Vaginal progesterone:}

In 250 women from U.K., Chile, Brazil, and Greece, with mostly (90\%) singleton gestations and TVU CL $\leq 15 \mathrm{~mm}$ at 20-25 weeks, of whom about $85 \%$ had no prior PTB, vaginal progesterone $200 \mathrm{mg}$ nightly started at 24 weeks until 34 weeks was associated with a $44 \%$ significant decrease in SPTB <34weeks (19\% vs 34\%; RR 0.56, 95\% CI 0.36-0.86), but no significant effect on neonatal morbidities (composite neonatal adverse outcome: RR 0.57, 95\% CI 0.23-1.31). (23) A subgroup analysis of only women without prior PTB confirmed significant 
benefit of progesterone in preventing PTB <34weeks (RR 0.54, 95\%CI 0.34-0.88). (23) The prevalence of TVU CL $\leq 15 \mathrm{~mm}$ in the population screened for the study was $1.7 \%$. Based on the frequency of short TVU CL and effectiveness for prevention of spontaneous PTB $<34$ weeks from the work of Fonseca et al, the number of women needed to be screened with CL in order to prevent one spontaneous PTB $<34$ weeks is approximately 387 , if all women with a $\mathrm{CL} \leq 15 \mathrm{~mm}$ receive vaginal progesterone. Once a TVU $\mathrm{CL} \leq 15 \mathrm{~mm}$ is identified, the number needed to treat to prevent one $\mathrm{PTB}<34$ weeks is about 7.

In 458 women with singleton gestations and TVU CL 10-20mm at 19-23 6/7 weeks, of whom about $84 \%$ had no prior PTB, vaginal progesterone 90mg daily started at 20-23 6/7 weeks until 36 6/7 weeks was associated with a 45\% significant reduction in PTB < 33 weeks (9 vs $16 \%$; RR $0.55,95 \%$ CI $0.33-0.92$ ), and $43 \%$ significant reduction in composite neonatal morbidity and mortality (8 vs 14\%; RR 0.57, 95\% CI 0.33-0.99). (24) The incidences of PTB < 28 and $<35$ weeks, and RDS, were also significantly decreased. Analysis of only women without prior PTB confirmed significant benefit of progesterone in preventing PTB $<33$ weeks (8 vs $15 \%$; RR $0.50,95 \%$ CI $0.27-0.90$ ). (24) The prevalence of CL $10-20 \mathrm{~mm}$ was $2.3 \%$ in the population screened. The study enrolled patients in 44 centers in 10 countries (largest enrollment from U.S., $46 \%$ of total), and the ethnic distribution of those included was about a third Caucasian, a third African-American, and a third Asian. Protocol violations may have influenced the outcomes, and the study was both industry- and NIH-sponsored. After evaluating data from this trial only, the FDA concluded that the study did not meet the statistical significance generally expected to support the approval of the product in the US market from a single trial. The FDA raised the issue of robustness in efficacy in the US subgroup as compared to overall efficacy in the trial, and stated that additional clinical work would be required to support the 
approval. (25) Based on the frequency of short CL and effectiveness for prevention of PTB $<33$ weeks from this study (24), the number of women needed to be screened with CL in order to prevent one PTB $<33$ weeks is approximately 604, if all women with a CL 10-20mm receive vaginal progesterone. Once a TVU CL 10-20mm is identified, the number needed to treat to prevent one PTB $<33$ weeks is about 14 . The study did not address the management of women with a $C L<10 \mathrm{~mm}$.

In a meta-analysis, including 554 singleton gestations, no prior PTB, and TVU CL $\leq$ $25 \mathrm{~mm}$ mostly before 25 weeks, vaginal progesterone was associated with a significant reduction in PTB < 33 weeks (RR 0.60, 95\% CI 0.39-0.92) and a non-significant reduction in composite neonatal morbidity and mortality (RR 0.70, 95\% CI 0.42-1.16). (26)

Two cost-effectiveness analyses evaluating universal cervical length screening in singleton gestations, to identify those with short CL eligible for vaginal progesterone, have been published so far. $(27,28)$ Both reported that such a strategy would be cost-effective. In one study, compared to other managements, including no screening, 'universal' sonographic screening of $\mathrm{CL}$ in singletons was predicted to results in a reduction of 95,920 preterm births $<37$ weeks annually in the US, and was actually cost-saving (almost $\$ 13$ billion saved). (27) Even varying the assumptions (e.g. the cost of vaginal progesterone or of TVU screening), universal screening was the preferred strategy $99 \%$ of the time. (27)

The other cost-effectiveness analysis targeted women with singleton gestation without prior PTB. A strategy of universal screening with a single TVU CL at 18-24 weeks and treatment with vaginal progesterone if the cervical length was $\leq 1.5 \mathrm{~cm}$, resulted in over $\$ 12$ million saved, 424 quality adjusted life-years (QALY) gained, and 22 neonatal deaths or long-term neurologic deficits prevented for every 100,000 women screened compared with no screening. Even varying 
the assumptions over a wide range of possible values (e.g. the cost of vaginal progesterone or of TVU screening), universal screening was cost-effective over 99\% of the time. (28) This costeffectiveness analysis initially addressed only women with a $\underline{\text { TVU }} \mathrm{CL} \leq 1.5 \mathrm{~mm}$. In an addendum, the authors mention that a re-analysis adding progesterone treatment for women with TVU CL between 1.6 to $2.5 \mathrm{~mm}$ did not change their conclusions, with the details of the reanalysis not provided.

In summary, in women with singleton gestations, no prior SPTB, and short TVU CL, vaginal progesterone is associated with reduction in PTB and composite perinatal morbidity and mortality. Based on these results $(23,24)$, if a TVU CL $\leq 20 \mathrm{~mm}$ is identified at $\leq 24$ weeks, vaginal progesterone can be offered for prevention of PTB. The 2 studies used different progesterone preparations and dosages. Vaginal progesterone $200 \mathrm{mg}$ suppository was used in the trial for $\mathrm{CL} \leq 15 \mathrm{~mm}$ (23), and 90mg gel for the trial for CL 10-20mm (24). There is insufficient evidence that any of the vaginal preparations or doses is superior, as they have not been compared. CL, cost, availability, and other factors may influence preferred dosing. $(27,28)$ A decision of whether to institute a policy of universal screening for short cervix with TVU in women with singleton gestations without prior PTB requires several careful considerations:

- The available trials have addressed efficacy of progesterone for women identified with a short cervix. There are no data regarding effectiveness of universal screening for short cervix followed by vaginal progesterone for those with a short cervix, compared to no screening. The only evidence in favor of such an approach is based on cost-effectiveness analyses. 
- It is possible that a proportion of women with a short cervix may be identified without a specific universal transvaginal ultrasound screening. This may result in a lower than estimated added benefit of universal screening over current practice of visualization of the cervix on all transabdominal ultrasound performed in the second trimester. Data is currently insufficient to suggest benefit, or harm, of transabdominal screening of CL for prevention of preterm birth using progesterone or any other intervention as therapy if a short CL is identified.

- Universal screening approach may not produce the same results in practice as those in a controlled trial. The latter may be due to differences in population, logistical differences in screening methods, stretching of the eligibility and management criteria (scope creep), and unintended consequences of universal screening. Performing multiple 'follow-up' scans, doing them outside of the studied gestational age (18-24 weeks), applying the treatment to women outside the studied CL range, or using other interventions for a short CL, such as bed rest or cerclage, may potentially result in adverse unintended consequences. The eligibility criteria were different between the 2 RCTs, and neither included all the women who had a CL below what is traditionally considered as short in the US $(<$ $25 \mathrm{~mm}$ ). The Fonseca et al. trial did not include women with a CL between 15 and $25 \mathrm{~mm}$, and the Hassan et al. trial did not include women with a $\mathrm{CL}<10 \mathrm{~mm}$ or between 20 and $25 \mathrm{~mm}$. Neither trial included women with CL > 20mm, and therefore there is no evidence that vaginal progesterone is beneficial in these women. $(23,24,26)$ It should be noted that only $1.7-2.3 \%$ of women were identified to have short CL in the two large trials published, $(23,24)$ but that the 
incidence of CL $\leq 20 \mathrm{~mm}$ at $22-24$ weeks in the largest blinded US study was $5 \%$.

(29) The use of different progesterone formulations (90mg gel and 200mg suppository) between the 2 trials should also be taken into account. There is no evidence that the two preparations are interchangeable in that the one which was efficacious in the 10-20 mm range would also be efficacious in those with a CL $<10 \mathrm{~mm}$. In a meta-analysis, both of these two preparations had similar significant efficacy. (26)

- If an approach of universal screening is to be adopted, then TVU CL screening needs to be done with proper technique and with quality assurance in order to be effective.

- There may be lack of availability of this screening test in some geographic areas. All of the above need to be taken into consideration when deciding on whether to change prenatal care for million of women by instituting universal screening with a single TVU assessment of CL at around 18-24weeks in women with a singleton gestation without prior spontaneous PTB. On the other hand, TVU CL screening of singleton gestations does fulfill many criteria for an effective screening test (Table 2). (30-32) A number of experts have recommended TVU CL universal screening. (33-35) This is based mostly, in addition to what is listed on Table 2, on the following facts:

- There is level 1 evidence of prevention of PTB and neonatal benefits based on treating with vaginal progesterone low-risk singleton gestations identified with TVU screening to have a short CL. 
- This strategy is not only beneficial in terms of improvement in health in a condition (PTB) of outmost importance to society, but also cost-effective, and in fact cost-saving.

- TVU CL is a safe, acceptable, reproducible and accurate screening test, with potentially widespread availability.

Therefore, both proponents and opponents of universal screening raise valid issues. Cervical length screening in singleton gestations without prior preterm birth cannot yet be mandated universally. Nonetheless, implementation of such a screening strategy should be viewed as reasonable, and can be considered by individual practitioners. Third-party payers should not deny reimbursements for this screening. Practitioners who decide to implement universal cervical length screening should follow strict guidelines:

- TVU CL needs to be performed with proper technique in order to yield accurate results, with quality control and monitoring. To ensure quality, the Perinatal Quality Foundation is setting up a program on the proper training for clinical use of TVU CL measurement.

- Randomized trials and cost-effectiveness studies were mostly based on performing a single TVU CL at 18-24 weeks on singleton gestations, and on using vaginal progesterone, either $90 \mathrm{mg}$ gel or $200 \mathrm{mg}$ suppository, as intervention when the TVU CL was $\leq 20 \mathrm{~mm}$ before 24 weeks. Clinicians should refrain from screening different populations, at different gestational ages, and from stretching the definition of short CL to include measurements above $20 \mathrm{~mm}$. There is also no evidence that other preparations (e.g. intramuscular 17P) or doses would be efficacious, even within the specified CL range. 


\section{- Singleton gestations with prior preterm birth, and unknown or normal CL?}

17P:

In 43 women with mostly singleton gestation ( $>90 \%)$ and either prior PTB or $>1$ prior spontaneous abortion, 17P 250mg IM weekly started as soon as prenatal care began was associated with significant reduction in $\mathrm{PTB}<37$ weeks and perinatal mortality, compared to placebo. (36)

In 463 women with singleton gestation and prior SPTB at 20-36 6/7 weeks of a singleton gestation, compounded 17P 250mg IM weekly started at 16-20 6/7 weeks was associated with reduction in the incidences of PTB $<35$ (RR $0.66,95 \%$ CI 0.54-0.81), PTB $<37$ and $<32$ weeks, as well as of supplemental oxygen and IVH, compared to placebo. (6) Based mostly on this clinical trial, 17P has been recommended for all women with prior SPTB 20-36 6/7 weeks $(3,5)$ The estimated number of prevented PTBs $<37$ weeks in the US by this policy is about 9,870 annually. (37)

While the best evidence for efficacy is for 17P to be started before 21 weeks, beneficial effects have been reported when $17 \mathrm{P}$ is started by $\leq 27$ weeks $(38,39) 17 \mathrm{P}$ should not be stopped early (eg <32 weeks), as this is associated with increased incidence of PTB. (40)

\section{Vaginal progesterone:}

In 142 women with singleton gestations and mostly prior PTB (>90\%), vaginal progesterone $100 \mathrm{mg}$ nightly from 24 to 34 weeks was associated with significant reduction in the incidences of PTB $<37$ weeks (RR 0.48, 95\% CI 0.25-0.96) and $<34$ weeks, as well as reduction in contraction frequency, compared to placebo. (41) 
In 659 women with singleton gestation and prior SPTB 20-35 0/7 weeks, vaginal progesterone $90 \mathrm{mg}$ every morning starting at 18-22 6/7 weeks and continued until 37 0/7 weeks was not associated with significantly different rates of PTB $<37,36,33,29$ weeks and neonatal morbidity and mortality. (7) Several women screened for this trial were excluded because of short CL. (7)

\section{Effect of progesterone on CL:}

In singleton gestations with prior PTB, 17P has not been associated with an effect on the development of short CL. (42) On the other hand, vaginal progesterone was associated with significant reduction in the incidence of short CL in women with singleton gestations and prior PTB. (16)

\section{Oral progesterone:}

In 148 women with singleton gestation and prior SPTB 20-36 6/7 weeks, oral progesterone $100 \mathrm{mg}$ twice a day was associated with significantly reduced rates of PTB $<37$ weeks and NICU admission compared to placebo. (43) In 33 women with singleton gestation and prior PTB 20-36 6/7 weeks, oral progesterone 400mg daily was associated with trend (but no significant differences) for reduced rates of PTB $<37$ weeks ( 26 vs $57 \%$; $\mathrm{p}=0.15$ ) and ventilator use ( 0 vs $21 \%$; $\mathrm{p}=0.07$ ) compared to placebo (44)

In summary, in women singleton gestation with prior SPTB, in which CL is unknown, progestogen administration is beneficial in preventing PTB. Although we have limited data comparing the different preparations of progestogens, there is at present stronger evidence of effectiveness for 17P than for vaginal progesterone, based on the 2 largest trials. $(6,7)$ Therefore, 17P 250mg IM weekly starting at 16-20weeks until 36 weeks should be recommended to women 
with singleton gestations and prior SPTB 20-36 6/7 weeks. In cases in which 17P is unavailable, other progesterone preparations may be considered. (41)

- Singleton gestations with prior PTB, and short CL?

17P:

There are no RCTs evaluating the effectiveness of 17P compared to placebo in women with singleton gestations, prior PTB, and short CL. In this population, 17P has only been evaluated as an adjunct or an alternative to cervical cerclage.

In singleton gestations with prior SPTB and a short $\underline{\text { TVU }}$ CL $<25 \mathrm{~mm}$ before 23 weeks, $17 \mathrm{P}$ was associated with statistically significant decrease in PTB $<24$ weeks and perinatal death in women not receiving cerclage in a secondary analysis of a cerclage trial (45). Beneficial effects of 17P were noted primarily for women with CL15-24.9 mm, while they were nonsignificant for women with $\mathrm{CL}<15 \mathrm{~mm}$. Overall, women with a cervical length $<25 \mathrm{~mm}$ had a $34 \%$ risk of PTB < 32 weeks if they received neither $17 \mathrm{P}$ nor cerclage, $25 \%$ if they received cerclage, $21 \%$ if they received $17 \mathrm{P}$, and $17 \%$ if they received both. (45) While these results were not statistically significant, they suggest that further research is needed to evaluate the relationship and possible cumulative beneficial effect of progesterone and cerclage.

In a randomized trial which did not recruit the planned sample size, $17 \mathrm{P}$ and cerclage had similar effects in preventing PTB in women with a $\underline{\text { TVU }} \mathrm{CL}<25 \mathrm{~mm}$, but cerclage was more beneficial in women with $\mathrm{CL}<15 \mathrm{~mm}$ (22). While cerclage seems to be more efficacious (lower RRs) for CL on the lower end of the range $(46,47)$, progesterone seems to be most efficacious for 'moderately' short CL. $(23,24)$

\section{Vaginal progesterone:}


In a secondary analysis of an RCT (7) evaluating just the 46 singleton gestations with prior SPTB $<35$ weeks and short TVU CL $<28 \mathrm{~mm}$ at 18-22 6/7 weeks, vaginal progesterone 90mg daily started at 18-23 6/7 weeks until 37 weeks was associated with significant decreases in the rates of both PTB $<32$ weeks and NICU admission, compared to placebo. (48)

In 71 singleton gestations with prior PTB, vaginal progesterone 100mg suppositories daily between 24-34weeks was associated with significant reduction in incidences of PTB $<37$ weeks (24\% vs 50\%; OR 3.11, 95\% CI 1.13-8.53) and <34 weeks (5.4\% vs 26.5\%; OR 6.30, 95\% CI 1.25-31.70), compared to placebo (49)

In a meta-analysis, including 169 singleton gestations with prior PTB and TVU CL $\leq$ $25 \mathrm{~mm}$ mostly before 25 weeks, vaginal progesterone was associated with a significant reduction in PTB < 33 weeks (RR 0.54, 95\% CI 0.30-0.98) and in composite neonatal morbidity and mortality (RR 0.41, 95\% CI 0.17-0.98). (26)

Based on the pooled results of five clinical trials, in 504 singleton pregnancies with prior spontaneous PTB at less than 34 weeks and TVU CL $<25$ mm before 24 weeks' gestation, cerclage was associated with a significant $30 \%$ reduction in the risk of PTB $<35$ weeks $(28 \%$ versus $41 \%$; RR, $0.70 ; 95 \% \mathrm{CI}, 0.55--0.89$ ) and a $36 \%$ reduction in composite perinatal mortality and morbidity (16\% versus $25 \%$; RR, 0.64; 95\% CI, 0.45-0.91) (8). Therefore screening women with singleton gestations with prior spontaneous PTB with TVU CL starting usually at 16 weeks and every 2 weeks until 23 weeks is suggested, so that cerclage can be offered for those who develop a TVU CL $<25 \mathrm{~mm}$. As the vast majority of women included in this meta-analysis and its included randomized trials did not receive $17 \mathrm{P}$, there is insufficient evidence to determine if the concurrent use of progesterone and cerclage offers an additive effect in reducing the risk of preterm birth in this group of women with prior preterm birth. (50) 
Therefore, the optimal management of the patient with progressive cervical shortening despite progesterone therapy remains uncertain.

In summary, 17P should be recommended to women with prior SPTB starting at 16 weeks, as described above. If the cervix shortens $<25 \mathrm{~mm}$ by TVU before 24 weeks in such a woman with singleton gestation and prior SPTB, there is insufficient evidence to assess efficacy of a different progesterone therapy, and therefore it is reasonable to continue 17P until 36 weeks, and to offer cervical cerclage.

\section{- Multiple gestations, and unknown or normal CL?}

17P:

In 77 women with twin gestation, 17P 250mg IM weekly from 28 to 33 weeks was not associated with any effect on PTB rates or perinatal morbidity and mortality, compared to placebo. (51)

In 655 women with DC twin gestation, of whom $<10 \%$ had prior PTB, 17P 250mg IM weekly starting at 16-20 weeks and ending at 35 weeks was not associated with any effect on PTB rates or perinatal morbidity and mortality in a NICHD-sponsored RCT, compared to placebo. (52)

In 30 women with twin gestation, of whom $27 \%$ had a prior PTB, 17P 250mg IM weekly starting at 20-30 weeks and ending at 34 weeks was associated with similar incidences of PTB < 35 weeks and $<30$ weeks, as well as similar rates of neonatal morbidity and mortality, compared to placebo. CL was not reported. (10) 
In 240 women with DC twin gestation, 17P 250mg IM weekly starting at 16-24 weeks until 34 weeks was associated with similar incidences of PTB and neonatal morbidity, compared to placebo (53)

Two RCTs have evaluated the effect of 17P in triplet gestations. In a total of about 190 triplet gestations, 17P 250mg IM weekly started at around 16-20/22 weeks gestations until 34/35 weeks was not associated with effects on incidence of PTB or perinatal morbidity and mortality compared to placebo. $(54,55)$

\section{Vaginal progesterone:}

In 500 women with twin gestation, vaginal progesterone $90 \mathrm{mg}$ daily starting at 24 weeks and continued for at least 10 weeks was not associated with significant effects in incidences of PTB or perinatal morbidity and mortality, compared to placebo. (56)

In 677 women with diamniotic twin gestation, vaginal progesterone $200 \mathrm{mg}$ pessaries starting at 20-24 weeks until 34 weeks were not associated with significant effects on incidences of PTB or perinatal complications, compared to placebo (57).

In 67 twin gestations, vaginal progesterone 100mg suppositories daily between 2434 weeks was associated with significant reduction in incidences of PTB $<37$ weeks ( $51 \%$ vs 79\%; OR 3.48, 95\% CI 1.16-10.46) but not <34 weeks (10\% vs 25\%; OR 2.90, 95\% CI 0.7611.20), compared to placebo. (49)

No RCT has yet been reported on the effect of vaginal progesterone on triplet gestations.

In summary, the evidence does not support the use of any type of progestogen for prevention of PTB in multiple gestations with unknown CL. In women with prior spontaneous PTB, and a current multiple gestation, some experts have suggested the use of 17P starting at 16 
weeks based on the historic risk factor (58), but there is insufficient evidence to make this a recommendation.

- Multiple gestations, and short CL?

17P:

In a secondary analysis of a trial involving women with dichorionic twin gestation, 52 women, of whom $18.5 \%$ had prior PTB, were identified to have a TVU CL of $\leq 35 \mathrm{~mm}\left(25^{\text {th }}\right.$ percentile) between 16-20weeks. 17P 250mg IM weekly starting at 16-20 weeks and ending at 35 weeks was associated with similar incidences of PTB $<35$ weeks $(64 \%$ vs $46 \%, \mathrm{p}=0.18)$, compared to placebo. (59)

\section{Vaginal progesterone:}

In a secondary analysis of a trial involving women with diamniotic twin gestation, 47 women, of whom 9\% had prior PTB, were identified to have TVU CL $\leq 30 \mathrm{~mm}$ between 20-24 weeks. Vaginal progesterone 200mg pessaries starting at 20-24 weeks until 34 weeks was not associated with an effect on PTB < 34 weeks (29\% vs 40\%: RR 0.63, 95\% CI 0.18-2.23), compared to placebo. (60)

In a meta-analysis, including 52 twin gestations found to have a TVU CL $<25 \mathrm{~mm} \leq 24$ weeks, vaginal progesterone was associated with similar incidence of PTB $<33$ weeks $(30 \%$ vs 45\%; RR 0.70, 95\% CI 0.34-1.44) and <35 weeks (52\% vs 62\%; RR 0.91, 95\% CI 0.57-1.46), but a significant reduction in composite neonatal morbidity and mortality (24\% vs 40\%, RR 0.56, 95\% CI 0.30-0.97), compared to placebo. (26)

In summary, there is insufficient evidence to assess the effect of progestogens in women with both multiple gestation and short CL. 


\section{- Preterm labor?}

\section{Primary tocolysis}

In 57 women admitted between 13-36weeks with contractions, progesterone 400mg

orally once was associated with a significant decrease in the frequency of contractions, but no PTB or neonatal outcomes were reported, compared to placebo. (61)

\section{Adjunctive tocolysis}

In 44 women with mostly singleton gestations ( $>90 \%)$ and threatened PTL at less than 35 weeks treated with ritodrine, natural progesterone 400mg orally q6hrs x $24 \mathrm{hrs}$ (then 400mg q8hrs for next $24 \mathrm{hrs}$, and then $300 \mathrm{mg}$ q8hrs onwards) was associated with similar rates of PTB, but with lower total dose of ritodrine administered and shorter maternal hospital stay compared to placebo. (62)

\section{Maintenance tocolysis}

\section{P:}

In 60 women with singleton gestation still pregnant after successful tocolysis for PTL, 17P $341 \mathrm{mg}$ twice weekly started at 25-33 6/7 weeks until 36 weeks was associated with significant reduction in the incidence of PTB $<37$ weeks (but not 35 weeks) and of risk of cervical shortening compared to no such treatment. (63)

In 188 women with singleton gestations still pregnant after successful tocolysis for PTL, 17P 500mg IM twice weekly started at 24-31 6/7 weeks until 36 weeks was associated with similar incidences of PTB $<37,<34$, and $<32$ weeks, and of perinatal morbidity and mortality compared to no such treatment (64)

Vaginal progesterone: 
In 70 women with singleton gestation still pregnant after successful tocolysis for PTL, vaginal progesterone $400 \mathrm{mg}$ daily until delivery was associated with longer latency until delivery, later gestational age at delivery (PTB was not reported), and RDS compared to no such treatment. (65)

In summary, there is currently insufficient evidence to recommend progesterone primarily for, or as an adjunct to, tocolysis.

\section{- PPROM?}

17P:

In 69 women with singleton gestations and PPROM at 24 to 30 weeks, 17 P $250 \mathrm{mg}$ IM is associated with no effect on interval to delivery, gestational age at delivery, or neonatal mortality and morbidity in a small RCT. (11)

\section{Vaginal progesterone:}

No RCT has evaluated the effect of vaginal progesterone in this population.

In summary, there is insufficient evidence to assess effect of progesterone in women with PPROM. In a woman who has been receiving 17P for prior spontaneous PTB, in the absence of evidence to the contrary, it is reasonable to continue $17 \mathrm{P}$ once membranes have ruptured.

\section{Conclusions}

Assessment of efficacy of progestogens for prevention of PTB should be done separately for each type of progestogens, with vaginal and intramuscular routes of administration the most studied types. Efficacy probably varies also depending on each different risk factor. In addition, dose, gestational age at initiation and termination, compliance, and other issues are factors that 
influence efficacy of progesterone for prevention of PTB. Therefore, singleton vs multiple gestation, prior history (e.g. prior PTB), short TVU CL (and degree of) or not, asymptomatic vs

PTL and PPROM, etc, are all factors which should be considered, as progestogens have different effects in populations with any one (or combination of) risk factor. Several meta-analyses have been published (4,66-68), but they either do not evaluate these studies according to the different populations just mentioned, or soon become out-of-date because of publications of new RCTs.

Recommendations for clinical use of progestogens for prevention of preterm birth: (Table 3 and Figure 1)

- There is insufficient evidence to recommend the use of progestogens in singleton gestations with no prior preterm birth, and unknown CL. (Level I and III evidence, level A recommendation)

$\circ$ In women with singleton gestations, no prior SPTB, and short TVU CL $\leq 20 \mathrm{~mm}$ at $\leq 24$ weeks, vaginal progesterone, either $90 \mathrm{mg}$ gel or $200 \mathrm{mg}$ suppository, is associated with reduction in PTB and perinatal morbidity and mortality, and can be offered in these cases. (Level I evidence, level A recommendation)

The issue of universal TVU CL screening of singleton gestations without prior PTB for the prevention of preterm birth remains object of debate. Cervical length screening in singleton gestations without prior preterm birth cannot yet be universally mandated. Nonetheless, implementation of such a screening strategy can be viewed as reasonable, and can be considered by individual practitioners. Given the impact on prenatal care and potential misuse of universal 
screening, stretching the criteria and management beyond those tested in RCTs should be prevented. Practitioners who decide to implement universal TVU CL screening should follow strict guidelines. Practitioners who choose to screen low-risk singleton gestations may consider offering vaginal progesterone, either $90 \mathrm{mg}$ gel or 200mg suppositories, for short TVU CL $\leq 20$ $\mathrm{mm}$ at $\leq 24$ weeks.(Level I and III evidence, level B recommendation)

○ In singleton gestations with prior SPTB 20-36 6/7 weeks, 17P 250mg IM weekly preferably starting at 16-20 weeks until 36 weeks is recommended. In these women, if the TVU CL shortens to $<25 \mathrm{~mm}$ before 24 weeks, cervical cerclage may be offered. (Level I and III evidence, level $A$ and $B$ recommendations)

- Progestogens have not been associated with prevention of PTB in multiple gestations, PTL, or PPROM. There is insufficient evidence to recommend the use of progestogens in women with any of these risk factors, with or without a short CL. Some experts offer 17P to women with a prior spontaneous PTB and a current multiple gestation, but there is insufficient data to evaluate the risks and benefits of this intervention in this population. (Level I, II and III evidence, level $B$ recommendation) 


\section{References}

1. Csapo A, Goodall M. Excitability, length tension relation and kinetics of uterine muscle contraction in relation to hormonal status. J Physiol 1954;126(2):384-95. (Level II-2)

2. Keirse MJNC. Progestogen administration in pregnancy may prevent preterm delivery. British J Obstet Gynaecol 1990;97:149-54. (Level I)

3. American College of Obstetricians and Gynecologists. Use of progesterone to reduce preterm birth. ACOG Committee Opinion No.419. Obstet Gynecol 2008;112:963-5. (Level III)

4. Dodd JM, Flenady V, Cincotta R, Crowther CA. Prenatal administration of progesterone for preventing preterm birth in women considered to be at risk of preterm birth. Cochrane Database of Systematic Reviews 2006, Issue 1. Art. No.: CD004947. DOI: 10.1002/14651858.CD004947.pub2. (Level I)

5. Kilpatrick SJ, for the Society for Maternal-Fetal medicine. Progesterone for the prevention of preterm birth. Contemp Obstet Gynecol 2009;6:32-3. (Level III) 
6. Meis PJ, Klebanoff M, Thom E, Dombrowski MP, Sibai B, Moawad AH, et al.

Prevention of recurrent preterm delivery by 17 alpha-hydroxyprogesterone caproate. N Engl J Med 2003;348:2379-85. (Level I)

7. O'Brien JM, Adair CD, Lewis DF, et al. Progesterone vaginal gel for the reduction of recurrent preterm birth: primary results from a randomized, double-blind, placebocontrolled trial. Ultrasound Obstet Gynecol 2007;30:687-96. (Level I)

8. Berghella V, Rafael TJ, Szychowski JM, Rust OA, Owen J. Cerclage for short cervix on ultrasonography in women with singleton gestations and previous preterm birth: a meta-analysis. Obstet Gynecol. 2011 Mar;117(3):663-71. (Level I)

9. Renthal NE, Chen NN, Williams KC, et al. miR-200 family and targets, ZEB1 and ZEB2, modulate uterine quiescence and contractility during pregnancy and labor. Proc Natl Acad Sci USA 2010;107:20828-33. (Level II-2)

10. Briery CM, Veillon EW, Klauser CK, Martin RW, Chauhan SP, Magann EF, Morrison JC. Progesterone does not prevent preterm births in women with twins. Southern Med J 2009;102:900-4. (Level I)

11. Briery CM, Veillon EW, Klauser CK, Martin RW, Magann EF, Chauhan SP, Morrison JC. Women with preterm premature rupture of the membranes do not benefit from weekly progesterone. Am J Obstet Gynecol 2011;204:54.e1-5. (Level I)

12. Zakar T, Mesiano S. How does progesterone relax the uterus in pregnancy? N Engl J Med. 2011;364(10):972-3. (Level II-2)

13. Peltier MR, Tee SC, Smulian JC. Effect of progesterone on proinflammatory cytokine production by monocytes stimulated with pathogens associated with preterm birth. Am J Reprod Immunol 2008;60:346-53. (Level II-2) 
14. Xu H, Gonzalez JM, Ofori E, Elovitz MA. Preventing cervical ripening: the primary mechanism by which pregestational agents prevent preterm birth? Am J Obstet Gynecol 2008;198:314.e1-8. (Level II-2)

15. Sfakianaki AK, Norwitz ER. Mechanisms of progesterone action in inhibiting prematurity. J Mat Fetal Neo Med 2006;19:763-72. (Level II-2)

16. O’Brien JM, DeFranco EA, Adair CD, Lewis DF, Hall DR, How H, et al. Effect of progesterone on cervical shortening in women at risk for preterm birth: secondary analysis from a multinational, randomized, double-blind, placebo-controlled trial. Ultrasound Obstet Gynecol 2009;34:653-9. (Level I)

17. Zakar T, Hertelendy F. Progesterone withdrawal: key to parturition. Am J Obstet Gynecol 2007;196(4):289-96. (Level II-2)

18. Resseguie LJ, Hick JF, Bruen JA, Noller KL, O’Fallon WM, Kurland LT. Congenital malformations among offspring exposed in utero to progestins, Olmsted County, Minnesota, 1936-1974. Fertil Steril 1985;43:514-19. (Level II-2)

19. Northen AT, Norman GS, Anderson K, Moseley L, et al.; for the National Institute of Child Health and Human Development (NICHD) Maternal-Fetal Medicine Units (MFMU) Network. Follow-up of children exposed in utero to 17 ahydroxyprogesterone caproate compared with placebo. Obstet Gynecol 2007;110(4):865-72. (Level I)

20. Hauth JC, Gilstrap LC 3rd, Brekken AL, Hauth JM. The effect of 17 alphahydroxyprogesterone caproate on pregnancy outcome in an active-duty military population. Am J Obstet Gynecol. 1983 May 15;146(2):187-90. (Level I) 
21. Grobman, et al, for the Eunice Kennedy Schriver National Institute of health and Human Development. Randomized controlled trial of progesterone treatment for preterm birth prevention in nulliparous women with cervical length less than $30 \mathrm{~mm}$. Am $\mathbf{J}$ Obstet Gynecol 2012;206:s367. (Level I)

22. Keeler SM, Kiefer D, Rochon M, Quinones JN, Novetsky AP, Rust O. A randomized trial of cerclage vs. $17 \alpha$-hydroxyprogesterone caproate for treatment of short cervix. J Perinal Med 2009;37:473-9. (Level I)

23. Fonseca EB, Celik E, Parra M, Singh M, Nicolaides KH. Progesterone and the risk of preterm birth among women with a short cervix. N Eng J Med 2007; 357: 462-469. (Level I)

24. Hassan SS, Romero R, Vidyadhari D, Fusey S, Baxter J, Khandelwal M, Vijayaraghavan J, Trivedi Y, Soma-Pillay P, Sambarey P, Dayal A, Potapov V, O'Brien J, Astakhov V, Yuzko O, Kinzler W, Dattel B, Sehdev H, Mazheika L, Manchulenko D, Gervasi MT, Sullivan L, Conde-Agudelo A, Phillips JA, Creasy GW; for the PREGNANT Trial. Vaginal progesterone reduces the rate of preterm birth in women with a sonographic short cervix: a multicenter, randomized, double-blind, placebo-controlled trial. Ultrasound Obstet Gynecol. 2011;38(1):18-31. (Level I)

25. US Food and Drug Administration. Advisory committees. http://www.fda.gov/AdvisoryCommittees/Calendar/ucm279859.htm. Last accessed on March 5, 2012. (Level III)

26. Romero R, Nicolaides K, Conde-Agudelo A, et al. Vaginal progesterone in women with an asymptomatic sonographic short cervix in the midtrimester decreases preterm 
delivery and neonatal morbidity: a systematic review and meta-analysis. Am J Obstet Gynecol 2011, doi:10.1016/j.ajog.2011.12.003. (Level I)

27. Cahill AG, Odibo AO, Caughey AB, Stamilio DM, Hassan SS, Macones GA, Romero R. Universal cervical length screening and treatment with vaginal progesterone to prevent preterm birth: a decision and economic analysis. Am J Obstet Gynecol. 2010;202:548.e1-8. (Level III)

28. Werner EF, Han CS, Pettker CM, Buhimschi CS, Copel JA, Funai EF, Thung SF. Universal cervical-length screening to prevent preterm birth: a cost-effectiveness analysis. Ultrasound Obstet Gynecol. 2011;38:32-7. (Level III)

29. Iams JD, Goldenberg RL, Meis PJ, Mercer BM, Moawad A, Das A, et al. The length of the cervix and the risk of spontaneous premature delivery. NEJM 1996;334(9):56772. (Level II-1)

30. Rafael TJ. Short Cervical Length. In: Preterm Birth: Prevention and Management, Berghella V. (Ed), Wiley-Blackwell, New York 2010.)

31. Carlan SJ, Richmond LB, O'Brien WF. Randomized trial of endovaginal ultrasound in preterm premature rupture of membranes. Obstet Gynecol 1997; 89:458.

32. Dutta RL, Economides DL. Patient acceptance of transvaginal sonography in the early pregnancy unit setting. Ultrasound Obstet Gynecol. 2003 Nov;22(5):503-7.)

33. Lockwood CJ. The real progesterone story. Contemp Ostet Gynecol 2011;5:10-5. (Level III)

34. Campbell S. Universal cervical-length screening and vaginal progesterone prevents early preterm births, reduces neonatal morbidity and is cost saving: doing nothing is no longer an option. Ultrasound Obstet Gynecol. 2011;38(1):1-9. (Level III) 
35. Combs CA Vaginal progesterone for asymptomatic cervical shortening and the case for universal screening of cervical length. AJOG 2012; DOI: 10.1016/j.ajog.2011.12.008 (Level III)

36. Johnson JW, Austin KL, Jones GS, Davis GH, King TM. Efficacy of 17alphahydroxyprogesterone caproate in the prevention of premature labor. N Engl J Med. 1975;293(14):675-80. (Level I)

37. Petrini JR, Callaghan WM, Klebanoff M, Green NS, Lackritz EM, Howse JL, Schwarz RH, Damus K. Estimated effect of 17 alpha-hydroxyprogesterone caproate on preterm birth in the United States. Obstet Gynecol. 2005 Feb;105(2):267-72. (Level III)

38. González-Quintero VH, Istwan NB, Rhea DJ, Smarkusky L, Hoffman MC, Stanziano GJ. Gestational age at initiation of 17-hydroxyprogesterone caproate (17P) and recurrent preterm delivery. J Matern Fetal Neonatal Med. 2007 Mar;20(3):249-52. (Level II-2)

39. How HY, Barton JR, Istwan NB, Rhea DJ, Stanziano GJ. Prophylaxis with 17 alphahydroxyprogesterone caproate for prevention of recurrent preterm delivery: does gestational age at initiation of treatment matter? Am J Obstet Gynecol 2007;197:260.e1-260.e4. (Level II-2)

40. Rebarber A, Ferrara LA, Harley ML, Istwan NB, Rhea DJ, Stanziano GJ, Saltzman DH. Increased recurrence of preterm delivery with early cessation of 17-alphhydroxyprogester-one caproate. Am J Obstet Gynecol 2007;196:224,e1-4. (Level II2)

41. da Fonseca EB, Bittar RE, Carvalho MH, Sugaib M. Prophylactic administration of progesterone by vaginal suppository to reduce the incidence of spontaneous preterm 
birth in women at increased risk: a randomized placebo-controlled double-blind study. Am J Obstet Gynecol 2003;188:419-24. (Level I)

42. Durnwald CP, Lynch CD, Walker H, Iams JD. The effect of treatment with 17 alphahydroxyprogesterone caproate on changes in cervical length over time. Am J Obstet Gynecol 2009;201:410.e1-5. (Level II-2)

43. Rai P, Rajaram S, Goel N, Ayalur Gopalakrishnan R, Agarwal R, Mehta S. Oral micronized progesterone for prevention of preterm birth. Int J Gynaecol Obstet 2009;104:40-3. (Level I)

44. Glover MM, McKenna DS, Downing CM, et al. A randomized trial of micronized progesterone for the prevention of recurrent preterm birth. Am J Perinat 2011;28:377-

81. (Level I)

45. Berghella V, Figueroa D, Szychowski JM, Owen J, Hankins GDV, Iams JD, Sheffield JS, Perez-Delboy A, Wing DA, Guzman ER, for the Vaginal Ultrasound Trial consortium. 17-alpha-hydroxyprogesterone caproate for the prevention of preterm birth in women with prior preterm birth and a short cervical length. Am J Obstet Gynecol 2010;202:351,e1-6. (Level II-1)

46. Owen J, Szychowski J. Can the optimal cervical length for placing ultrasound-indicated cerclage be identified? Am J Obstet Gynecol 2011;204:s198-9. (Level II-1)

47. Owen J, Hankins G, Iams JD, Berghella V, Sheffield JS, Perez-Delboy A, Egerman RS, Wing DA, Tomlinson M, Silver R, Ramin SM, Guzman ER, Gordon M, How HY, Knudtson EJ, Szychowski JM, Cliver S, Hauth JC. Multicenter randomized trial of cerclage for preterm birth prevention in high-risk women with shortened midtrimester cervical length. Am J Obstet Gynecol 2009;201:375.e1-8. (Level I) 
48. DeFranco EA, O'Brien JM, Adair CD, et al. Vaginal progesterone is associated with a decrease in risk for early preterm birth and improved neonatal outcome in women with a short cervix: a secondary analysis from a randomized, double-blind, placebocontrolled trial. Obstet Gynecol 2007;30:697-705. (Level II-1)

49. Cetingoz E, Cam C, Sakalli M, et al. Progesterone effects on preterm birth in high-risk pregnancies: a randomized placebo-controlled trial. Arch Gynecol Obstet 2011;283:423-29. (Level I)

50. Berghella V, Figueroa D, Szychowski JM, Owen J, Hankins GD, Iams JD, Sheffield JS, Perez-Delboy A, Wing DA, Guzman ER; Vaginal Ultrasound Trial Consortium. 17alpha-hydroxyprogesterone caproate for the prevention of preterm birth in women with prior preterm birth and a short cervical length. Am J Obstet Gynecol. 2010 Apr;202(4):351.e1-6.

51. Hartikainen-Sorri AL, Kauppila A, Tuimala R. Inefficacy of 17 a-hydroxyprogestrone caproate in the prevention of prematurity in twin pregnancy. Obstet Gynecol 1980;56:692-5. (Level I)

52. Rouse DJ, Caritis SN, Peaceman AM, Sciscione A, Thom EA, Spong CY, Varner M, Malone F, Iams JD, Mercer BM, Thorp J, Sorokin Y, Carpenter M, Lo J, Ramin S, Harper M, Anderson G; National Institute of Child Health and Human Development Maternal-Fetal Medicine Units Network. A trial of 17 alpha-hydroxyprogesterone caproate to prevent prematurity in twins. N Engl J Med. 2007 Aug 2;357(5):454-61. (Level I) 
53. Combs CA, Garite T, Maurel K, Das A, Porto M; for the Obstetrix Collaborative Research Network. 17-hydroxyprogesterone caproate for twin pregnancy: a doubleblind, randomized clinical trial. Am J Obstet Gynecol 2011;204:221.e1-8. (Level I)

54. Caritis SN, Rouse DJ, Peaceman AM, et al.; for the Eunice Kennedy Shriver National Institute of Child Health and Human Development (NICHD), Maternal-Fetal Medicine Units Network (MFMU). Prevention of preterm birth in triplets using 17 alpha-hydroxyprogesterone caproate: A randomized controlled trial. Obstet Gynecol 2009;113(2):285-92. (Level I)

55. Combs CA, Garite T, Maurel K, et al.; for the Obstetrix Collaborative Research Network. Failure of 17-hydroxyprogesterone to reduce neonatal morbidity or prolong triplet pregnancy: a double-blind, randomized clinical trial. Am J Obstet Gynecol 2010;248.e1-9. (Level I)

56. Norman JE, Mackenzie F, Owen P, Mactier H, et al. Progesterone for the prevention of preterm birth in twin pregnancy (STOPPIT): a randomized, double-blind, placebocontrolled study and meta-analysis. Lancet 2009;373:2034-40. (Level I)

57. Rode L, Klein K, Nicolaides KH, Krampl-Bettelheim E, Tabor A; PREDICT Group. Prevention of preterm delivery in twin gestations (PREDICT): a multicenter, randomized, placebo-controlled trial on the effect of vaginal micronized progesterone. Ultrasound Obstet Gynecol. 2011;38:272-80. (Level I)

58. Iams JD, Berghella V. Care for women with prior preterm birth. Am J Obstet Gynecol. 2010;203:89-100. (Level III)

59. Durnwald CP, Momirova V, Rouse DJ, et al. For the Eunice Kennedy Shriver National Institute of Child Health and Human Development Maternal-Fetal Medicine Units 
Network. Second trimester cervical length and risk of preterm birth in women with twin gestations treated with 17- $\alpha$ hydroxyprogesterone caproate. J Matern Fetal Neonat Med 2010;e1-5. (Level II-1)

60. Klein K, Rode L, Nicolaides KH, Krampl-Bettelheim E, Tabor A; PREDICT Group. Vaginal micronized progesterone and risk of preterm delivery in high-risk twin pregnancies: secondary analysis of a placebo-controlled randomized trial and metaanalysis. Ultrasound Obstet Gynecol 2011;38:281-7. (Level II-1)

61. Erny R, Pigne A, Prouvost C, Gamerre M, Malet C, Serment H, et al. The effects of oral administration of progesterone for premature labor. American Journal of Obstetrics and Gynecology. American Journal of Obstetrics and Gynecology 1986;154(3):525-9. (Level I)

62. Noblot G, Audra P, Dargent D, Faguer B, Mellier G. The use of micronized progesterone in the treatment of menace of preterm delivery. European Journal of Obstetrics \& Gynecology and Reproductive Biology 1991;40(3):203-9. (Level I)

63. Facchinetti F, Paganelli S, Comitini G, Dante G, Volpe A. Cervical length changes uring preterm cervical ripening: effects of 17- $\alpha$-hydroxyprogesterone caproate. Am J Obstet Gynecol 2007;196:453,e1-4. (Level I)

64. Rozenberg P, Chauveaud A, Deruelle P, et al. Prevention of preterm delivery after successful tocolysis in preterm labour by 17 alpha-hydroxyprogesterone caproate: a randomized controlled trial. Am J Obstet Gynecol 2012: in press. (Level I)

65. Borna S, Sahabi N. Progesterone for maintenance tocolytic therapy after threatened preterm labour: a randomized controlled trial. Aust N Z J Obstet Gynaecol. 2008;48(1):58-63. (Level I) 
66. Su LL, Samuel M, Chong YS. Progestational agents for treating threatened or established preterm labour. Cochrane Database of Systematic Reviews 2010, Issue 1. Art. No.: CD006770. DOI: 10.1002/14651858.CD006770.pub2. (Level I)

67. MacKenzie R, Walker M, Armson A, Hannah ME. Progesterone for the prevention of preterm birth among women at increased risk: a systematic review and meta-analysis of randomized controlled trials. Am J Obstet Gynecol 2006;194:1234-42. (Level I)

68. Sanchez-Ramos L, Kaunitz AM, Delke I. Progestational agents to prevent preterm birth: A meta-analysis of randomized controlled trials. Obstet Gynecol 2005;105:273-9. (Level I) 
The quality of evidence for each included article was evaluated according to the categories outlined by the U.S. Preventative Services taskforce.

I Properly powered and conducted randomized controlled trial (RCT); well-conducted systematic review or meta-analysis of homogeneous RCTs

\section{II-1 Well-designed controlled trial without randomization}

II-2 Well-designed cohort or case-control analytic study

II-3 Multiple time series with or without the intervention; dramatic results from uncontrolled experiments

III Opinions of respected authorities, based on clinical experience; descriptive studies or case reports; reports of expert committees

Recommendations were graded in the following categories:

Level A The recommendation is based on good and consistent scientific evidence. 
Level B The recommendation is based on limited or inconsistent scientific evidence.

Level C The recommendation is based on expert opinion or consensus.

This opinion was developed by the Publications Committee of the Society for Maternal-Fetal Medicine with the assistance of Vincenzo Berghella, and was approved by the Executive Committee of the Society on March 11, 2012. Dr. Berghella, and each member of the Publications Committee (Vincenzo Berghella, M.D. [Chair], Sean Blackwell, M.D. [Vice-Chair], Brenna Anderson, M.D., Suneet P. Chauhan, M.D., Joshua Copel, M.D., Cynthia Gyamfi, M.D., Donna Johnson M.D., Brian Mercer M.D., George Saade, M.D., Hyagriv Simhan, M.D., Lynn Simpson, M.D., Joanne Stone, M.D., Alan Tita, MD, Michael Varner, M.D, Ms. Deborah Gardner) have submitted a conflict of interest disclosure delineating personal, professional, and/or business interests that might be perceived as a real or potential conflict of interest in relation to this publication.

Disclaimer: The practice of medicine continues to evolve, and individual circumstances will vary. This opinion reflects information available at the time of its submission for publication and is neither designed nor intended to establish an exclusive standard of perinatal care. This 
publication is not expected to reflect the opinions of all members of the Society for MaternalFetal Medicine.

\section{Legend to figure}

Algorithm for use of progestogens in prevention of preterm birth in clinical care 


\section{$\underline{\text { Table } 1}$}

\section{Proposed mechanisms of action reported for progestogens to prevent preterm birth ${ }^{9-17}$}

\section{Mechanisms}

Stimulate transcription of ZEB1 and ZEB2, which inhibit connexin 43 ( a gap-junction protein that helps synchronize contractile activity) and the oxytocin-receptor gene

Decrease prostaglandin synthesis, infection-mediated cytokine production (antiinflammatory effects) by the fetal membranes/placenta

Changes in progesterone receptor (PR)-A and PR-B expression (decreased PR-A/PR-B ratio keeps uterus quiescent)

Membrane-bound PR in myometrium

Progesterone receptors, when stimulated by progesterone, help selected gene promotion, or prevent the binding of other factors

Interfere with cortisol-mediated regulation of placental gene expression

Non-genomic pathways

Reduce cervical stromal degradation in the cervix

Alter barrier to ascending inflammation/infection in the cervix

Reduce contraction frequency in the myometrium

Attenuate response to hemorrhage/inflammation in the decidua

Alter estrogen synthesis in the fetal membranes/placenta

Alter fetal endocrine-mediated effects

ZEB1 and ZEB2, zinc finger E-box binding homeobox proteins 1 and 2. 
Table 2

Cervical length as a screening test in singleton gestations

\begin{tabular}{|c|c|c|}
\hline \multicolumn{3}{|c|}{$\begin{array}{c}T V U C L \\
\text { Screening test criteria }\end{array}$} \\
\hline $\begin{array}{c}\text { Characteristic of screening test: } \\
\text { Disease }\end{array}$ & Comments & $\begin{array}{l}\text { TVU fulfills } \\
\text { criteria }\end{array}$ \\
\hline Disease is clinically important & $\begin{array}{l}\text { PTB: \#1 cause of perinatal mortality } \\
\text { and morbidity in developed countries; } \\
\text { associated with one million deaths } \\
\text { annually worldwide }\end{array}$ & Yes \\
\hline Disease is clearly defined & Birth $<37$ weeks & Yes \\
\hline Disease prevalence is well known & $12 \%$ in US, about $10 \%$ worldwide & Yes \\
\hline $\begin{array}{l}\text { Disease natural history is known / } \\
\text { Recognizable early asymptomatic } \\
\text { phase }\end{array}$ & $\begin{array}{l}\text { First cervical changes associated with } \\
\text { later PTB occur at the internal os, and } \\
\text { can only be detected early by } \\
\text { ultrasound }\end{array}$ & Yes \\
\hline \multicolumn{3}{|l|}{ Screening } \\
\hline Screening technique well-described & Described in several articles $(30,31)$ & Yes \\
\hline Screening is safe and acceptable & $\begin{array}{l}\text { TVU is safe even in women with } \\
\text { PPROM (30); } 99 \% \text { of women would } \\
\text { have TVU again; <2\% have severe } \\
\text { pain (33) }\end{array}$ & Yes \\
\hline $\begin{array}{l}\text { Screening has a reasonable cutoff } \\
\text { identified }\end{array}$ & $\begin{array}{l}20 \mathrm{~mm} \text { is the } 5^{\text {th }} \text { percentile, } 25 \mathrm{~mm} \text { is } \\
\text { the } 10 \% \text { percentile in the general US } \\
\text { population }(30)\end{array}$ & Yes \\
\hline Results are reproducible (reliable) & $\begin{array}{l}<10 \% \text { intra- and inter- observer } \\
\text { variability }\end{array}$ & $\begin{array}{l}\text { Yes; extremely } \\
\text { important to } \\
\text { control quality } \\
\text { of TVU CL }\end{array}$ \\
\hline Results are accurate (valid) & $\begin{array}{l}\text { Better than manual exam; predictive in } \\
\text { all populations studied }\end{array}$ & Yes \\
\hline \multicolumn{3}{|l|}{$\begin{array}{c}\text { Intervention, cost-effectiveness, } \\
\text { and feasibility }\end{array}$} \\
\hline 'Early' intervention is effective & $\begin{array}{l}\text { Two positive randomized trials both } \\
\text { reported that using vaginal }\end{array}$ & Yes \\
\hline
\end{tabular}




\begin{tabular}{|l|l|l|}
\hline & $\begin{array}{l}\text { progesterone for short CL is effective } \\
\text { in preventing PTB }(23,24,26)\end{array}$ & \\
\hline $\begin{array}{l}\text { Screening and treating abnormals is } \\
\text { cost-effective }\end{array}$ & $\begin{array}{l}\text { Two cost-effectiveness manuscripts } \\
\text { published }(27,28)\end{array}$ & $\begin{array}{l}\text { Yes, in fact } \\
\text { cost-saving }\end{array}$ \\
\hline $\begin{array}{l}\text { Facilities for screening are readily } \\
\text { available }\end{array}$ & $\begin{array}{l}\text { All pregnancies are offered an } \\
\text { ultrasound for fetal anatomy screening } \\
\text { at around 18-24 weeks }\end{array}$ & $\begin{array}{l}\text { Yes, but must } \\
\text { be properly } \\
\text { organized }\end{array}$ \\
\hline $\begin{array}{l}\text { Facilities for treatment are readily } \\
\text { available }\end{array}$ & $\begin{array}{l}\text { Vaginal progesterone is easily } \\
\text { administered as outpatient }\end{array}$ & Yes \\
\hline
\end{tabular}

TVU, transvaginal cervical length; CL, cervical length; PTB, preterm birth.

\section{$\underline{\text { Table } 3}$}

Current SMFM recommendations regarding use of progestogens for prevention of preterm birth

\begin{tabular}{|l|l|}
\hline Population & Recommendation regarding use of \\
progestogens \\
\hline Asymptomatic & \\
\hline Singletons without prior SPTB & No evidence of effectiveness \\
and unknown or normal TVU CL & \\
\hline Singletons with prior SPTB & 17P 250mg IM weekly from 16-20 weeks until 36 \\
Singletons without prior SPTB & Vaginal progesterone 90mg gel or 200mg \\
but CL $\leq \mathbf{2 0 m m}$ at $\leq \mathbf{2 4}$ weeks & suppository daily from diagnosis of short CL until \\
& 36 weeks \\
\hline Multiple gestations & No evidence of effectiveness \\
\hline Symptomatic & \\
\hline PTL & No evidence of effectiveness \\
\hline
\end{tabular}


17P, 17-alpha hydroxyl-progesterone caproate; SPTB, spontaneous preterm birth; TVU, transvaginal ultrasound; CL, cervical length 